\title{
WebSite Canvas Model: propuesta de un modelo visual para la ideación estratégica de sitios web
}

\author{
Carles Sanabre*, Rafael Pedraza-Jiménez*, Lluís Codina* \\ *Universitat Pompeu Fabra \\ Correo-e: carles.sanabre@upf.edu | ORCID iD: https://orcid.org/0000-0001-7711-8005 \\ Correo-e: rafael.pedraza@upf.edu | ORCID iD: https://orcid.org/0000-0002-6918-6910 \\ Correo-e:lluis.codina@upf.edu | ORCID iD: https://orcid.org/0000-0001-7020-1631
}

Recibido: 07-12-2017; 2a versión: 23-03-2018; Aceptado: 09-04-2018.

Cómo citar este artículo/Citation: Sanabre, C.; Pedraza-Jiménez, R.; Codina, L. (2018). WebSite Canvas Model: propuesta de un modelo visual para la ideación estratégica de sitios web. Revista Española de Documentación Científica, 41 (4): e221. https:// doi.org/10.3989/redc.2018.4.1542

Resumen: A partir del denominado Canvas Model, se propone un modelo para la ideación estratégica de sitios web. Consiste en una herramienta visual, que hemos denominado WebSite Canvas Model, que permite identificar los aspectos clave de la estrategia de un sitio web, representándolos de forma sintetizada en un lienzo o canvas. En este trabajo se describen los apartados que componen nuestra propuesta, y se testea su utilización mediante su aplicación a dos casos de uso reales. Se concluye que esta herramienta puede ofrecer a los responsables de la concepción de un sitio web un instrumento eficiente para identificar, debatir y consensuar las características que el sitio web debe tener para lograr sus objetivos. Igualmente, puede complementar otras herramientas de análisis heurístico de sitios web, siendo una herramienta útil tanto para profesionales como para académicos que utilicen sistemas heurísticos en sus estudios.

Palabras clave: calidad web; evaluación heurística de sitios web; ideación web; estrategia web; modelo estratégico de sitio web; herramienta visual estratégica; diseño web; negocio web; modelo canvas para sitios web; lienzo del sitio web; análisis web.

\section{WebSite Canvas Model: a visual proposal for strategic website conception}

Abstract: Taking the so-called Canvas Model as the starting point, a new model for the strategic conception of websites is proposed, consisting of a visual tool, that we have called Website Canvas Model, which allows the identification of key aspects of a website's strategy, presenting them in a synthesized form on a canvas. This work describes the elements that form this model, also showing the way they work together. Subsequently, the model has been validated by applying it in two real use cases. The conclusion is that this tool can offer, to those in charge for the design of a website, an efficient tool for identifying, discussing and agreeing about what characteristics the website must have in order to achieve its objectives. Likewise, it can complement other tools for heuristic evaluation of websites, so being useful for both professionals and academics that use heuristic systems in their studies.

Keywords: web quality; heuristic evaluation of websites; website conception; web strategy; strategic website model; strategic visual tool; web design; web business model; website canvas model; website model; web analysis.

Copyright: (c) 2018 CSIC. Este es un artículo de acceso abierto distribuido bajo los términos de la licencia de uso y distribución Creative Commons Reconocimiento 4.0 Internacional (CC BY 4.0). 


\section{INTRODUCCIÓN}

Los modelos de canvas o lienzos han sido muy utilizados desde la propuesta original del Business Model Canvas por Osterwalder y Pigneur (2010). Consiste en una herramienta para el diseño de modelos de negocio, cuyo carácter sintético, visual y colaborativo ha propiciado su éxito y popularidad.

De hecho, su uso se ha adaptado a distintos contextos. Algunos ejemplos son: el Business Model You (Osterwalder y otros, 2012), bajo el objetivo de la reorientación profesional; el Learning Canvas Model, utilizado para definir modelos de aprendizaje; el Gamification Model Canvas (Mora y otros, 2015), destinado al diseño de acciones de gamificación, el Lean Canvas para emprendimiento (Maurya, 2012), o el Platform Design Canvas (Cicero, 2013), que se orienta al diseño de plataformas de creación de valor. Estas diversas aplicaciones y usos han confirmado la validez de este sistema en los entornos académico, empresarial y profesional (Montalvo-Castro, 2016).

Este artículo presenta el WebSite Canvas Model, una adaptación del modelo de Canvas desarrollado por los autores de este trabajo, y que consideramos útil para el análisis y la concepción de sitios web. Para desarrollar nuestra propuesta, en primer lugar hemos llevado a cabo una intersección del marco teórico del Business Canvas Model, de la de la especificación de requerimientos (PedrazaJiménez y otros, 2013) y de la evaluación heurística de sitios web (Jiménez-Iglesias y otros, 2017; Pedraza-Jiménez y otros, 2016).

En segundo lugar, una vez obtenido un modelo inicial, fue puesto a prueba con una batería de análisis comparativos de sitios web. En tercer lugar, una vez refinado el modelo tras los análisis anteriores, hemos llevado a cabo dos estudios de caso para mostrar su viabilidad. Las metodologías utilizadas en este trabajo han consistido, por tanto, en una revisión sistematizada de los ámbitos mencionados, y en un análisis comparativo de dos estudios de caso que se muestran en este artículo.

\subsection{La concepción estratégica de sitios web}

Un sitio web debe ser ideado a partir de la estrategia de la organización (Pedraza-Jiménez y otros, 2013). Teniendo en cuenta que es un desarrollo transversal, es decir, que afecta a toda la organización, precisa ser diseñado en base a unos objetivos bien establecidos, consensuados, y responder a los criterios de calidad deseados (Pedraza-Jiménez y otros, 2016). Además, las empresas tienen cada vez más interés en "saber si su web posee elementos de calidad, más allá de la evidencia de la calidad de contenidos o de la vistosidad del diseño." (Codina, 2000).

Sobre los criterios de calidad de los sitios web existen numerosos estudios, tal como exponen en su trabajo Hernández y otros (2009). El objetivo de estos estudios sobre el sitio web ha sido principalmente valorar su eficacia, la calidad de sus contenidos, así como medir la calidad en relación con la comunicación con los usuarios, pero no evaluar su estrategia. Asimismo, estas herramientas no están pensadas para la ideación. Tampoco tienen en cuenta aspectos relativos a la estrategia, como son la propuesta de valor de un sitio web, sus socios clave o sus fuentes de ingresos entre otros factores de negocio.

A diferencia de los trabajos anteriores, esta propuesta parte de la premisa de que un sitio web, aunque esté construido bajo criterios de calidad técnicos, puede no responder al objeto para el cual ha sido ideado y fracasar en su cometido. Con frecuencia esto se debe a la falta de una estrategia y objetivos bien establecidos para el sitio web. Es en este aspecto en el que se centra este trabajo, proponiendo una herramienta que facilita una correcta ideación previa al desarrollo web. Es más, el modelo que se presenta también es de aplicación en el contexto de un rediseño, en el que conviene estudiar si se mantiene o revisa la estrategia original del sitio (Campos-Freire, 2015), procesos y sistemas de gestión de la información (creación, recuperación, circulación y acceso).

El artículo parte de un repaso a los esquemas más relevantes sobre el diseño web y las disciplinas que abordan, para luego dar paso a los objetivos del trabajo. A continuación se detallan las metodologías utilizadas para el desarrollo del modelo, mostrando a continuación el resultado, que es el WebSite Canvas Model. Tras la presentación de la herramienta, se explica su validación mediante dos casos de uso, para finalmente exponer las conclusiones.

La ideación de sitios web se ha abordado con diferentes metodologías. Tenemos propuestas clásicas, pero aún vigentes, que se caracterizan por ser anteriores a la eclosión de la Web social. Una de las primeras y más importantes por su enorme influencia es debida a Jakob Nielsen (1994 y 1999).

Además, corresponde mencionar a Garrett (2011) cuya principal aportación fue integrar casi todas las disciplinas relacionadas con el diseño web (como, por ejemplo, el diseño de la experiencia del usuario, el diseño de la interfaz o la implementación del desarrollo) sin exigir excesivas depen- 
dencias entre ellas. Por otra parte, Olsen (2003) presenta un modelo con elementos que, sin estar relacionados, toman en consideración algunos aspectos estratégicos básicos del sitio web.

Otro autor de referencia es Dalton (2007), que propone un sistema de ideación de sitios web que hace énfasis en las necesidades de los usuarios y los objetivos empresariales de la organización. En esta misma línea se pronuncian Rosenfeld y MorviIle (2006), que señalan la importancia de determinar qué estrategias persigue un negocio antes de definir la arquitectura de la información de su web. De ahí la importancia de alinear la estrategia de la organización con la arquitectura del sitio web.

Por su parte, Hernández y otros (2010), a partir de una extensa revisión bibliográfica, concluyen que los aspectos claves del diseño web son: la buscabilidad en la Web, la velocidad de acceso, la usabilidad, la calidad de contenido, la interactividad y la capacidad transaccional. Otras propuestas más recientes, como la de Kaur (2014) en su Web Quality Model Cube consideran que la calidad de un sitio web reside en los aspectos técnicos y en el contenido. Destacamos también el trabajo de análisis de Piñero-Naval y otros (2017), sobre las sedes web municipales de España. En su estudio plantean el diseño web como "un constructo complejo, formado por los principios de apariencia visual, arquitectura de la información y usabilidad, que representan los elementos nucleares a valorar en la planificación y desarrollo de un sitio web."

Todas estas propuestas se centran principalmente en aspectos técnicos $y / o$ funcionales de un sitio web. A diferencia de nuestro modelo, no tienen en cuenta globalmente los factores estratégicos del sitio web. Por tanto, la herramienta que proponemos a continuación se caracteriza por su utilidad para la concepción, el diseño y la implementación de un sitio web conforme a sus requerimientos estratégicos. Por último, cabe destacar un estudio muy completo y muy reciente de los principales modelos de análisis de sitios web llevados a cabo por Jiménez-Iglesias y otros autores (2017).

\section{OBJETIVOS}

El objetivo de este trabajo es doble. Por un lado, consiste en presentar el modelo que hemos denominado "WebSite Canvas Model" (en adelante WSCM), que consideramos una herramienta visual para la concepción e ideación de sitios web. A tal fin, se describe el proceso de creación de este modelo, los apartados que lo conforman, y el modo en que puede ser aplicado.
Por otro lado, se pretende validar la utilidad de este modelo. Para ello, se presentan dos casos de uso reales de esta herramienta. Se ha decidido presentar dos casos de uso de sitios web con características muy distintas para mostrar el funcionamiento del WSCM en dos contextos diferentes. EI WSCM se considerará validado si la herramienta demuestra ser útil y novedosa para detallar los factores claves de la estrategia de ideación de estos sitios web.

Estos objetivos pueden concretarse en las siguientes preguntas de investigación:

- P.1. ¿Es posible trasladar el denominado Canvas Model al ámbito de la ideación y diseño de sitios web?

- P.2. ¿Cuáles son las principales características en las que debe hacer énfasis ese modelo?

- P.3. ¿Es factible la validación de un modelo con estas características a través de casos de estudio?

\section{METODOLOGÍA}

La creación del WSCM se realizó en cuatro fases. En primer lugar, se realizó una extensa revisión bibliográfica, gracias a la cual se identificaron muchos de los modelos de referencia que se han mencionado en los antecedentes. Estos modelos fueron de utilidad para detectar que existía una carencia en relación con la concreción estratégica del sitio web, aspecto que ha sido incorporado y es central en esta propuesta.

En segundo lugar, se realizó y analizó un conjunto de ocho entrevistas semiestructuradas. Se entrevistó a los responsables de ocho destinos turísticos españoles y a los respectivos técnicos responsables de sus sitios web oficiales. Concretamente, de los destinos turísticos: Región de Murcia, Ciudad de Madrid, Galicia, Rías Baixas, Sitges, La Rioja, Málaga y Tarragona. Las entrevistas se realizaron en las sedes de las respectivas organizaciones entre los meses de marzo a julio de 2014.

En tercer lugar, la propuesta está fundamentada en la observación experta (Denzin y Lincoln, 2011). El desarrollo de más de un centenar de sitios web (desde el año 1996 hasta el año 2017), y la propuesta de una decena de sistemas de análisis para la evaluación de la calidad de sitios web (desde el año 2006 hasta el año 2017), han servido a los autores para concretar y formular este modelo.

Por último, se han desarrollado dos casos de uso en los que se ha aplicado la herramienta WebSite 
Canvas Model. El primero de ellos realizado en junio de 2016, con el sitio web corporativo de Piris, un distribuidor de componentes electrónicos y mecánicos. El segundo realizado en octubre 2015 con la tienda online CalperetMitjans.com, gestionada por un agricultor que vende directamente su cosecha a los consumidores. Ambos casos se caracterizan por presentar escenarios reales de diseño e implementación web, y han permitido testear y validar esta herramienta de ideación.

\section{RESULTADOS}

A continuación, se detallan los resultados obtenidos a partir de los métodos mencionados.

\subsection{Resultados de las entrevistas}

En las entrevistas realizadas se dialoga sobre diferentes aspectos relacionados con el ciclo de vida del sitio web. De ellas, se desprende que la concepción de los sitios web es con frecuencia una tarea tediosa y compleja, tal como ya apuntaban trabajos anteriores (Rodríguez-Martínez y otros, 2010). Uno de los en- trevistados lo expresa muy bien en la siguiente frase al referirse a las tareas que aborda el personal de los diferentes sitios web oficiales de turismo de Galicia.

"Esto no es algo estanco. Todo se entrelaza, unos se dedican a negocio, otros a la comunicación, otros a la estrategia de marca, otros a la informática. Es una colaboración entre todas las partes de una empresa".

La tabla I recoge las principales problemáticas señaladas por los entrevistados. Como puede observase éstas afectan a los procesos de concepción y desarrollo, mantenimiento y evaluación de los sitios web. Aspectos que como veremos son abordados por el modelo que proponemos.

\subsection{WebSite Canvas Model}

Como se ha podido comprobar, los resultados de las entrevistas constatan la necesidad de los profesionales de disponer de un sistema para la ideación de sitios web. Nuestra propuesta trata de dar respuesta a esta necesidad. A continuación, se presentan y describen los elementos que componen este nuevo modelo.

Tabla I. Problemáticas detectadas en las entrevistas

\begin{tabular}{|c|c|}
\hline Problemáticas detectadas en las entrevistas & Áreas estratégicas afectadas del sitio web \\
\hline Falta de planteamiento estratégico consensuado & - Propuesta de valor \\
\hline Carencias en la identificación de públicos & $\begin{array}{l}\text { - Segmentos de clientes } \\
\text { - Relación con los clientes } \\
\text { - Enfoque Social, Móvil y tratamiento del alcance } \\
\text { geográfico del sitio }\end{array}$ \\
\hline $\begin{array}{l}\text { Mantenimiento del sitio } \\
\text { Actualizaciones }\end{array}$ & $\begin{array}{l}\text { - Socios Clave } \\
\text { - Recursos Clave }\end{array}$ \\
\hline Mala indexación en buscadores & - SEO (Posicionamiento orgánico en buscadores) \\
\hline Falta colaboración actores del sector & $\begin{array}{l}\text { - Socios Clave } \\
\text { - Segmentos de clientes }\end{array}$ \\
\hline Dificultades en comunicar la propuesta de valor & - Propuesta de valor \\
\hline Dificultad en la definir y comunicar la marca & $\begin{array}{l}\text { - Tratamiento de la marca y la promesa comercial } \\
\text { - El Discurso persuasivo en el sitio }\end{array}$ \\
\hline Problemática en la definición de la arquitectura del sitio & $\begin{array}{l}\text { - SEO (Posicionamiento orgánico en buscadores) } \\
\text { - Arquitectura }\end{array}$ \\
\hline El enfoque en las redes sociales & $\begin{array}{l}\text { - Enfoque Social, Móvil y tratamiento del alcance } \\
\text { geográfico del sitio. }\end{array}$ \\
\hline La adaptación del sitio a los móviles & $\begin{array}{l}\text { - Enfoque Social, Móvil y tratamiento del alcance } \\
\text { geográfico del sitio }\end{array}$ \\
\hline Saber que hacen los competidores & - Benchmarking \\
\hline Falta de enfoque comercial & $\begin{array}{l}\text { - Propuesta de Valor } \\
\text { - Retorno de la inversión } \\
\text { - Discurso persuasivo }\end{array}$ \\
\hline Falta de indicadores del retorno de la inversión & - Retorno de la inversión \\
\hline Falta de indicadores de calidad del sitio & $\begin{array}{l}\text { - Sistemas de análisis e índices de calidad estratégica } \\
\text { y técnica }\end{array}$ \\
\hline
\end{tabular}


El WSCM consta de catorce apartados. Nueve de ellos tienen su origen en el modelo en el que está inspirado, el Business Canvas Model (Osterwalder y otros, 2012). No obstante, en nuestra propuesta estos apartados son redefinidos para adaptar su uso al contexto de la ideación y el desarrollo web. Además, el WSCM incorpora cinco apartados adicionales que abordan otras especificidades de la web. A continuación, la tabla II ofrece una explicación detallada de estos apartados.

Todos estos apartados forman parte de la estrategia global de un sitio web. Algunos de ellos guardan una estrecha relación entre sí. Este sería el caso, por ejemplo, de la "estructura de costes" que debe estar compensada por la "fuente de in- gresos" del sitio web. A continuación, la figura 1 muestra estas relaciones entre los diferentes apartados del WSCM. En ella, se agrupan juntos los apartados más directamente relacionados entre sí. Aunque debe constatarse que, en su conjunto, todos los apartados del modelo se influencian y condicionan mutuamente.

De este modo, comprobamos que el modelo establece una fuerte dependencia entre la "Actividad clave", los "Socios clave", y los "Recursos clave" de un sitio web. Es decir, existe una relación de dependencia entre "qué hacemos en nuestro sitio web" (su actividad), "con quién lo hacemos" (sus socios), y los "recursos que vamos a utilizar para ello".

Tabla II. Apartados del WebSite Canvas Model

\begin{tabular}{|c|c|}
\hline \multicolumn{2}{|c|}{ Apartados del WebSite Canvas Model } \\
\hline 1. Actividad clave & $\begin{array}{l}\text { Son las actividades que nos permiten hacer llegar al cliente la propuesta de valor de la } \\
\text { organización y cómo ésta se traslada al sitio web. } \\
\text { Para una tienda online de cervezas artesanas, su actividad clave seria trasladar el valor } \\
\text { de la selección exclusiva de sus productos, comercializarlos y hacerlos llegar a los } \\
\text { domicilios de sus clientes. }\end{array}$ \\
\hline 2. Socios clave & $\begin{array}{l}\text { El apartado, socios clave y alianzas, hace referencia a aquellos colaboradores esenciales } \\
\text { para el éxito del proyecto, complementando las capacidades de la organización. } \\
\text { Por ejemplo, tomamos en consideración un diario digital de ámbito nacional. Sus socios } \\
\text { clave podrían ser cibermedios locales que aportan contenido editorial. También la } \\
\text { empresa que gestione su publicidad. }\end{array}$ \\
\hline 3. Recursos clave & $\begin{array}{l}\text { Los recursos clave son aquellos elementos esenciales para llevar a término y mantener } \\
\text { el sitio web. Puede formar parte de este apartado todo lo relacionado con la tecnología } \\
\text { y estabilidad del sistema (socios tecnológicos e infraestructuras) así como el equipo } \\
\text { humano. } \\
\text { Si continuamos con el caso de la tienda de cervezas artesanas, los recursos clave podrían } \\
\text { ir desde el personal dedicado a actualizar y publicar el stock de cervezas, así como el } \\
\text { equipo SEO y de marketing del sitio web. }\end{array}$ \\
\hline 4. Relación con los clientes & $\begin{array}{l}\text { El apartado de relación con los clientes se centra en el modo en que serán atendidos los } \\
\text { potenciales clientes. Definiendo la relación con los clientes en el sitio web (formularios, } \\
\text { chat, etc.) } \\
\text { Por ejemplo, una compañía de transporte ferroviario de pasajeros puede optar por } \\
\text { atender a los clientes en su web utilizando chatbots, con sistemas automatizados o } \\
\text { incluso con inteligencia artificial. }\end{array}$ \\
\hline 5. Segmentos de clientes & $\begin{array}{l}\text { En este bloque se explican los segmentos de mercado a los que se dirige el negocio y a } \\
\text { los que orienta el sitio web. } \\
\text { Por ejemplo, una empresa de recambios de automóvil, que comercializa su catálogo en } \\
\text { su sitio web para clientes, fabricantes, talleres o particulares, deberá definir la forma de } \\
\text { trasladar esta segmentación en su sitio web. }\end{array}$ \\
\hline 6. Canal & $\begin{array}{l}\text { En el apartado denominado canal, se define la interrelación del sitio con otros canales, } \\
\text { tales como las redes sociales, el punto de venta, etc. } \\
\text { Por ejemplo, una universidad virtual debería definir su estrategia combinando su } \\
\text { actividad docente y de comunicación tanto en su sitio web (campus virtual) como en las } \\
\text { redes sociales y dispositivos móviles. }\end{array}$ \\
\hline 7. Estructura de costes & $\begin{array}{l}\text { La estructura de costes determina el precio de desarrollar y mantener el sitio web. Como } \\
\text { podrían ser el coste de los servidores, del servicio de seguridad para evitar ciberataques } \\
\text { y las nóminas de equipo de redacción del contenido, entre otros. }\end{array}$ \\
\hline
\end{tabular}




\begin{tabular}{|c|c|}
\hline \multicolumn{2}{|c|}{ Apartados del WebSite Canvas Model } \\
\hline 8. Fuente de ingresos & $\begin{array}{l}\text { Este apartado detalla cómo el sitio web aporta valor para retornar la inversión a } \\
\text { la organización. Por ejemplo, para el sitio web de un gestor administrativo, el sitio } \\
\text { web puede suponer una herramienta de captación de nuevos clientes. Mientras que } \\
\text { para el caso del diario digital, lo serían los ingresos de la publicidad y las cuotas de } \\
\text { subscriptores. }\end{array}$ \\
\hline 9. Propuesta de valor & $\begin{array}{l}\text { Este apartado trata sobre cómo generamos valor en la solución que ofrecemos al mercado } \\
\text { y cómo se traslada al sitio web. } \\
\text { Por ejemplo, un diario online que decide que su propuesta de valor reside en su } \\
\text { especialización en los ámbitos político y económico, y que en consecuencia incorpora } \\
\text { como articulistas a prestigiosos expertos en estas disciplinas. }\end{array}$ \\
\hline 10. Benchmarking & $\begin{array}{l}\text { El benchmarking tiene como objetivo la identificación de las mejores prácticas en sitios } \\
\text { web de referencia, así como el estudio de las debilidades de los sitios web competidores. } \\
\text { Continuando con el ejemplo del diario online podría, de este modo, descubrir buenas } \\
\text { prácticas aplicables en su organización y detectar debilidades de sus competidores como, } \\
\text { por ejemplo, temáticas escasamente abordadas. } \\
\text { O para el ejemplo de la tienda de cervezas, que detecta que los principales competidores } \\
\text { desatienden alguna gama determinada, como podría ser la cerveza artesana sin gluten. } \\
\text { De este modo, el sitio web puede explotar las debilidades detectadas y superar a los } \\
\text { competidores y a la vez adoptar las buenas prácticas de éstos. }\end{array}$ \\
\hline 11. Branding y promesa & $\begin{array}{l}\text { El apartado denominado Branding y promesa, trata la presencia de la marca en el sitio } \\
\text { web, y la promesa o beneficio clave que la empresa o servicio ofrece al usuario. Como } \\
\text { ejemplo podemos tomar la promesa de algunas cabeceras existentes: ser el diario online } \\
\text { líder de información en español o autodefinirse como el diario de los lectores influyentes. } \\
\text { Otros ejemplos se dan en marketplaces muy populares, que hacen explícita su promesa } \\
\text { con eslóganes como "el comercio global comienza aquí". }\end{array}$ \\
\hline 12. Discurso persuasivo & $\begin{array}{l}\text { El discurso persuasivo define el tono y la estrategia del discurso que se da hacia el } \\
\text { usuario en el sitio web. Por ejemplo, algunos cibermedios exponen abiertamente su } \\
\text { carácter crítico, progresista y de izquierdas y, por el contrario, otros apuestan por un } \\
\text { discurso más conservador. }\end{array}$ \\
\hline $\begin{array}{l}\text { 13. Estrategia SEO, } \\
\text { arquitectura y usabilidad }\end{array}$ & $\begin{array}{l}\text { Por otro lado, la estrategia SEO y la arquitectura del sitio deben definirse antes del } \\
\text { desarrollo, durante la etapa de identificación del mercado y público objetivos. Además, } \\
\text { este apartado presta atención a la usabilidad y la accesibilidad del sitio, aspectos } \\
\text { relacionados directamente con el posicionamiento orgánico y la arquitectura. Por } \\
\text { ejemplo, en el caso del diario online, y siguiendo una praxis habitual en este tipo } \\
\text { de medios, habría que definir una estrategia que permitiera diferenciar los títulos de } \\
\text { las noticias (títulos noticiosos) de los títulos SEO (el título que aparece en la pestaña } \\
\text { del navegador cuando leemos una noticia y que tiene gran incidencia sobre nuestro } \\
\text { posicionamiento orgánico). } \\
\text { Otra práctica por ejemplo, para una agencia de viajes online, podría consistir en } \\
\text { identificar y posicionar aquellos destinos turísticos en que los competidores no están } \\
\text { bien indexados. }\end{array}$ \\
\hline 14. SOLOMO & $\begin{array}{l}\text { El apartado SOLOMO está dedicado al enfoque social, local y móvil del sitio web. Tiene en } \\
\text { cuenta la estrategia a seguir en las plataformas sociales, la orientación a sus mercados } \\
\text { locales, y al uso en plataformas móviles. Un cibermedio, por ejemplo, puede optar por } \\
\text { compartir sus artículos en plataformas sociales, realizar notificaciones de novedades a } \\
\text { los usuarios que dispongan de la app del diario y organizar conferencias invitando a sus } \\
\text { lectores según geolocalización. }\end{array}$ \\
\hline
\end{tabular}


Figura 1. Estructura del WebSite Canvas Model

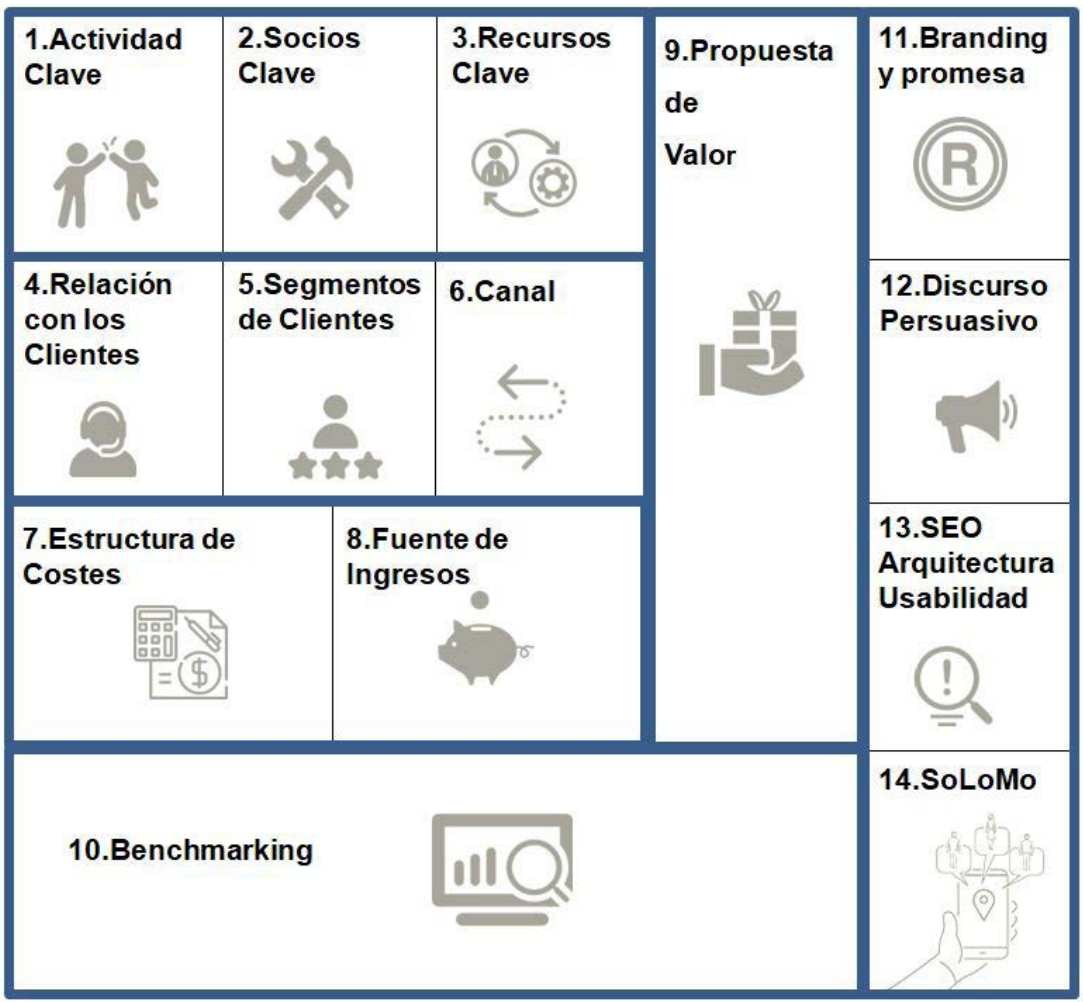

En cuanto al modo de uso de este modelo, se propone aplicar el WSCM siguiendo el orden planteado en la figura 1. La tabla III concreta este orden atendiendo a las fases del proceso de ideación de un sitio web. No obstante, este orden es flexible y podría variar si los responsables o la naturaleza del sitio web lo requieren.
Como puede comprobarse (tabla III), el modelo se articula en un orden formado por seis bloques (enumerados de $\mathrm{a}-\mathrm{f}$ ). Parte de aquellos apartados relacionados con la función del sitio web, es decir, de su actividad clave y de los socios necesarios para desarrollarla, así como de los recursos clave para su desarrollo y mantenimiento.

Tabla III. Orden de aplicación del WSCM

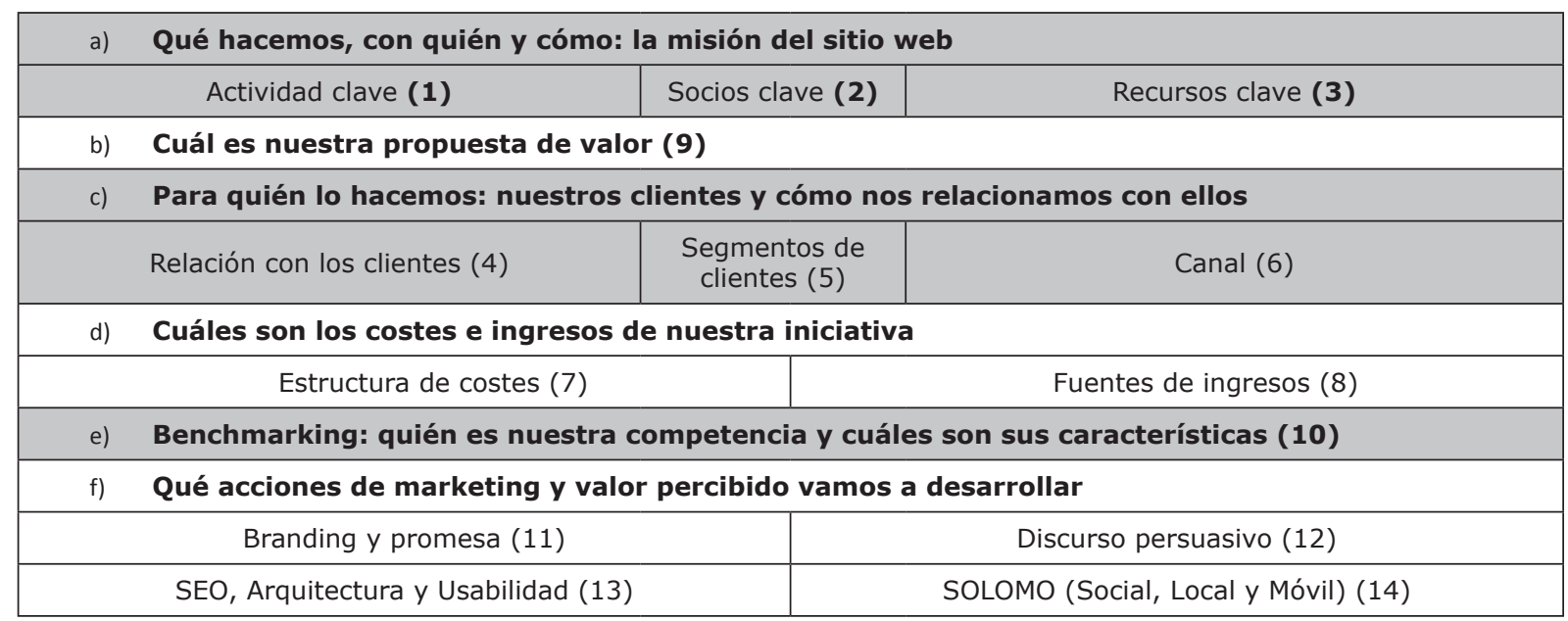


A continuación, se idea la estrategia del canal (que incluye la interrelación con las redes sociales) y que se relaciona con la definición de los segmentos de clientes y las formas de relacionarse con éstos.

Para la sostenibilidad del sitio, es necesario asumir e identificar una estructura de costes, que vendrá compensada por los ingresos que genere el sitio web, bien de forma directa (ventas) o bien aportando otro retorno de la inversión (por ejemplo, captando nuevos clientes).

La propuesta de valor es un elemento transversal que define la manera en que el sitio web traslada el valor de la organización al usuario. Asimismo, el benchmarking aporta información útil sobre el comportamiento de los competidores que puede afectar a toda o parte de nuestra estrategia.

El último bloque, agrupa apartados que atañen al marketing y la imagen que deseamos transmitir a través del sitio web. Así, el apartado Branding y promesa se encarga de definir el enfoque y el tratamiento de la marca de la organización, así como de comunicar la promesa o beneficio clave que se da al usuario.

Por su parte la estrategia SEO (posicionamiento orgánico en los buscadores), la arquitectura de la información, y la usabilidad son aspectos que deberían tener su propia estrategia previa al desarroIlo. Por ejemplo, una determinada elección de palabras clave para el SEO incide en la arquitectura del sitio. Asimismo, el discurso persuasivo, alineado con los anteriores apartados, define la argumentación general del discurso y el tono con que el sitio se dirige al usuario.

Por último, el enfoque Social, Móvil y Local determina cómo se relaciona el sitio web con aquellas plataformas sociales en las que tiene presencia. También concreta cómo adapta su contenido a los diferentes dispositivos móviles y sus funcionalidades (por ejemplo, este aspecto es especialmente importante para aquellos sitios web que identifican y sacan provecho de la localización de sus usuarios).

Todos estos elementos en su conjunto constituyen nuestro sistema o modelo para la ideación y el análisis estratégico de un sitio web.

\section{CASOS DE USO}

Es importante destacar que el WebSite Canvas Model no es solo un modelo teórico. Este sistema ha sido validado mediante su aplicación a casos reales de diseño y rediseño de sitios web. Concretamente, la empresa ideaRed (http://ideared.eu/) ha utilizado esta metodología en varios de sus pro- yectos de desarrollo. A continuación, destacamos algunos aspectos relevantes detectados tras su aplicación en los sitios web de dos empresas: Piris. com y Calperetmitjans.com.

La aplicación del modelo WSCM en la ideación de estos sitios web se realiza aplicando el siguiente procedimiento:

1. Se presenta y explica la herramienta WSCM a la organización o empresa interesada.

2. Se detalla la dinámica de trabajo, basada en un diseño colaborativo entre el staff de la compañía con la ayuda del consultor externo.

3. Se elabora un lienzo que resume los aspectos claves de la estrategia de la empresa (es decir, los requerimientos estratégicos) que se desean trasladar al desarrollo de su sitio web.

4. El lienzo resultante se consensua y valida por todas las partes implicadas en el desarrollo del sitio web.

5. Se implementa el desarrollo del sitio web.

A continuación, se presentan los dos casos de uso realizados para validar el modelo WSCM.

\subsection{Caso de uso del WSCM para Piris.com}

Piris S.A. es una empresa dedicada a la distribución de componentes eléctricos, mecánicos y sistemas electrónicos. Para la ideación de su nuevo sitio web, desarrollado en julio de 2016, se utilizó el WSCM. La formalización de su modelo estratégico requirió tres fases, que se desplegaron durante la primera semana de junio del mismo año:

1. Reunión grupal con el personal de la organización: consistió en una sesión de trabajo grupal, dirigida por el consultor experto y el equipo directivo de la organización, en este caso formado por el Director General, el Director Adjunto, el responsable técnico y el responsable del área comercial.

2. Análisis de la información recopilada y benchmarking: A partir de la identificación de los sitios web de referencia y competidores se realizó un análisis de éstos para identificar buenas prácticas y debilidades en ellos. Este análisis se centró en aspectos tales como la experiencia de usuario, indexación de sus contenidos en los buscadores, funcionamiento de los sistemas de atención al usuario, etc.

3. Formalización de los distintos análisis en el modelo visual WebSite Canvas Model. 
La aplicación del WSCM permitió al equipo directivo visualizar, compartir y debatir aquellos elementos y apartados claves en la ideación del sitio web. Tal como veremos a continuación, el WSCM de Piris (Figura 2) fue decisivo en las decisiones estratégicas que se trasladaron al desarrollo del sitio web.

De todos los apartados, destacamos a continuación aquéllos que han tenido mayor relevancia en el caso de Piris.com. Comenzamos con los apartados actividad clave, propuesta de valor y recursos clave, dado que los tres aportan resultados estrechamente interrelacionados, y claves para el diseño del sitio.

El apartado actividades clave permitió acotar claramente la actividad de la compañía: comercialización y distribución de componentes eléctricos, mecánicos y electrónicos, que pasa a ser el eslogan que acompaña al logotipo de la empresa en el sitio web. Continuando con los productos que distribuye la empresa, y gracias a la definición de la propuesta de valor, (consistente en la diversificación del producto en una extensa gama), se decidió idear un sistema de navegación facetado que permite acceder a todos los productos tanto navegando por taxonomías de sectores industriales (electrodo- mésticos, electromedicina, iluminación, etc.) como a través de categorías de producto (elementos de conexión, motores, resistencias, etc.), tal como se observa en la Figura 3.

Asimismo, para poder disponer de una extensa y documentada gama de productos, el sitio precisa de unos recursos clave, que el WSCM los concreta en el equipo responsable de la gestión de los contenidos, los proveedores de los productos (que aportan parte de la documentación técnica), y un buscador que facilita la búsqueda de productos.

El WSCM fue también clave en el apartado segmentos de clientes, pues gracias al uso del modelo se identificaron 3 grandes segmentos de clientes. Esto se reflejó en el enfoque del sitio, creando secciones y contenidos de valor para cada segmento. Estableciendo accesos directos a secciones dedicadas a "fabricantes", "instaladores" y "laboratorios y consultorías" (Figura 4). Es importante mencionar que el segmento de "laboratorios y consultorías" se incorporó como sección al sitio web gracias al WSCM. Este segmento supone un tráfico de gran calidad para el site, pues son los laboratorios los que analizan los componentes y actúan como prescriptores para los fabricantes de electrodomésticos, automóviles, calefacción, electromedicina, etc.

Figura 2. El WebSite Canvas Model de Piris.com

\begin{tabular}{|c|c|c|c|c|c|}
\hline $\begin{array}{l}\text { 1.Actividad } \\
\text { Clave } \\
\text { Comercializacion y } \\
\text { distribución de } \\
\text { componentes } \\
\text { eléctricos, mecánicos } \\
\text { y electrónicos. }\end{array}$ & \multicolumn{2}{|c|}{$\begin{array}{l}\text { 2.Socios } \\
\text { Clave } \\
\text { Desarrollo web } \\
\text { Hosting y SEO. } \\
\text { s. Empresariales: } \\
\text { Proveedores, } \\
\text { instaladores } \\
\text { Fabricantes } \\
\text { Prescriptores. }\end{array}$} & $\begin{array}{l}\text { 3.Recursos } \\
\text { Clave } \\
\text { Equipo responsable } \\
\text { de contenidos. } \\
\text { Proveedores (por } \\
\text { contenido). } \\
\text { Noticias. } \\
\text { Buscador dentro del } \\
\text { website. }\end{array}$ & $\begin{array}{l}\text { 9.Propuesta } \\
\text { de Valor } \\
\text { Doble } \\
\text { clasificación de } \\
\text { los productos por } \\
\text { categorias y } \\
\text { funciones. } \\
\text { Informacion clara } \\
\text { y aspecto visual. }\end{array}$ & $\begin{array}{l}\text { 11. Branding } \\
\text { y promesa } \\
\text { Gran gamma de } \\
\text { componentes } \\
\text { mecanicos y } \\
\text { electrónicos. } \\
\text { Rapidez en servicio. }\end{array}$ \\
\hline $\begin{array}{l}\text { 4.Relación } \\
\text { con los } \\
\text { Clientes } \\
\text { Formulario web. } \\
\text { correo electronico } \\
\text { y teleffono. }\end{array}$ & \multicolumn{2}{|c|}{$\begin{array}{l}\text { 5.Segmentos } \\
\text { de Clientes } \\
\text { SAT/Instaladores } \\
\text { fabricantes, } \\
\text { laboratorios y } \\
\text { centros de } \\
\text { investigacion, que } \\
\text { pueden actuar como } \\
\text { prescriptores. }\end{array}$} & $\begin{array}{l}\text { 6.Canal } \\
\text { Internet web y } \\
\text { móvil. }\end{array}$ & $\begin{array}{l}\text { Información } \\
\text { adicional de los } \\
\text { productos. } \\
\text { Servicio de } \\
\text { calidad. } \\
\text { Rápidos en } \\
\text { tiempo de } \\
\text { respuesta. }\end{array}$ & $\begin{array}{l}\text { 12. Discurso } \\
\text { Persuasivo } \\
\text { Calidad en producto } \\
\text { y servicio. } \\
\text { Claridad en la } \\
\text { información técnica. }\end{array}$ \\
\hline \multicolumn{2}{|c|}{$\begin{array}{l}\text { 7. Estructura de } \\
\text { Costes } \\
\text { Alojamiento web-Servers. } \\
\text { Costos de infraestructura. } \\
\text { Costos de personal (Redacción). } \\
\text { Compra de software. } \\
\text { Acciones de Marketing digital } \\
\text { (SEO, SEM. SMM). }\end{array}$} & $\begin{array}{l}\text { 8. Fue } \\
\text { Ingres }\end{array}$ & $\begin{array}{l}\text { te de } \\
\text { os } \\
\text { btadas por } \\
\text { ide LEAD. }\end{array}$ & $\begin{array}{l}\text { Seguimiento de } \\
\text { los pedidos. } \\
\text { Flexibles en las } \\
\text { necesidades del } \\
\text { cliente. } \\
\text { Dlversificación del } \\
\text { producto. gama } \\
\text { extensa de } \\
\text { productos. }\end{array}$ & $\begin{array}{l}\text { 13.SEO - AI } \\
\text { Usabilidad } \\
\text { Buscador de } \\
\text { productos. } \\
\text { Fichas de productos } \\
\text { completas. } \\
\text { Arquitectura por } \\
\text { funcionalidad del } \\
\text { componente y por } \\
\text { sector de uso. } \\
\end{array}$ \\
\hline $\begin{array}{l}\text { 10. Benchm } \\
\text { Descuidan el SEO, } \\
\text { calidad, links rotos. }\end{array}$ & king & ompe & $\begin{array}{l}\text { on de los contenic } \\
\text { is no tienen versic }\end{array}$ & $\begin{array}{l}\text { enes de mala } \\
\text { de su sitio web. }\end{array}$ & $\begin{array}{l}\text { 14.SoLoMo } \\
\text { Redes sociales } \\
\text { profesionales. } \\
\text { Enfoque al } \\
\text { mercado nacional. } \\
\text { Version movill del } \\
\text { sitio. }\end{array}$ \\
\hline
\end{tabular}


Figura 3. Captura de pantalla. Sistema de navegación facetado con distintas categorías de producto

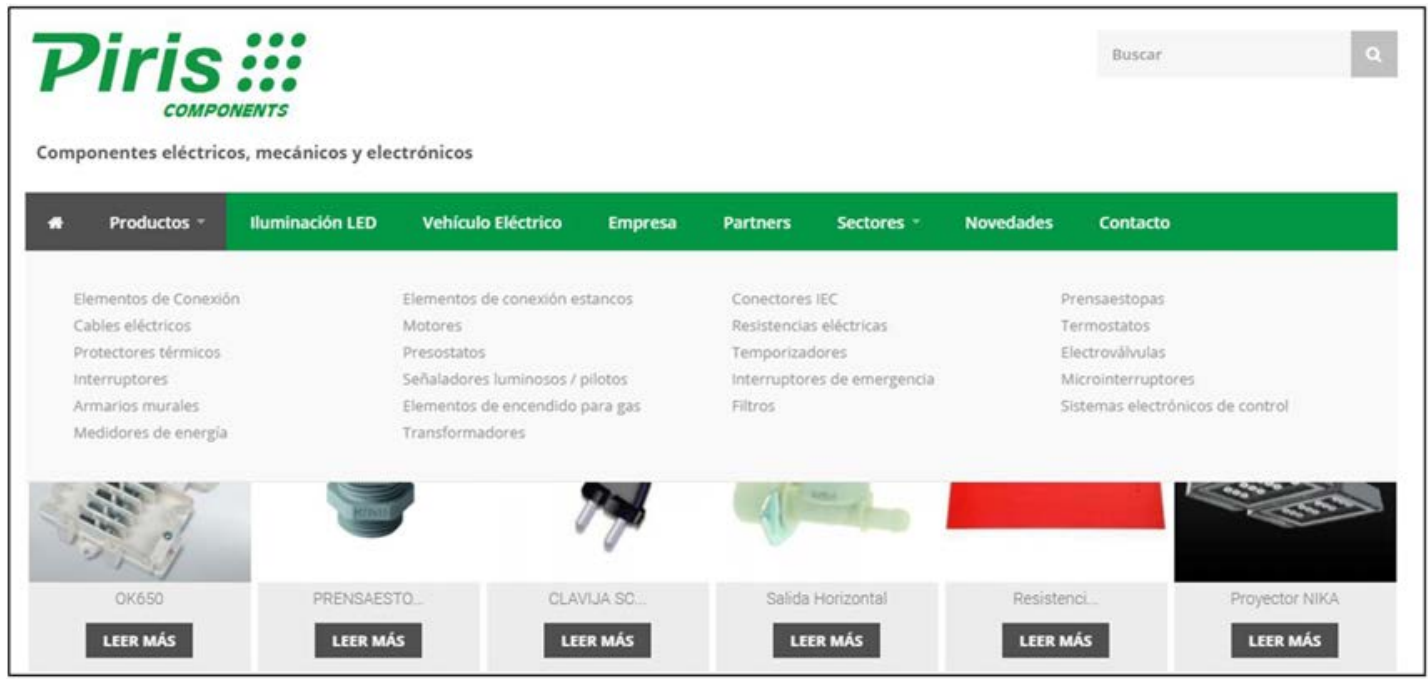

Figura 4. Implementación del apartado "Segmento de clientes" en la página web

\begin{tabular}{|c|c|c|c|}
\hline $\begin{array}{l}\text { 5. Segmentos } \\
\text { de clientes } \\
\text { SAT / Instaladores: aire } \\
\text { acondicionado, } \\
\text { calefacción } \\
\text { mantenimiento. LEO } \\
\text { Fabricantes } \\
\text { Laboratorios y centros } \\
\text { de investigación, que } \\
\text { pueden actuar como }\end{array}$ & $\begin{array}{l}\text { Nuestros clientes } \\
\text { En piris damos senvicio a fabricantes. si desea } \\
\text { informadón sobre un proyecto a medida póngase en } \\
\text { contacto con nosotros. } \\
\text { Más información. }\end{array}$ & $\begin{array}{l}\text { C INSTALADORES } \\
\text { ¿Es instaladon? JNecesita más información sobre } \\
\text { nuestros productos? PÓngase en contacto con nosotrosy } \\
\text { le atenderemos lo antes posible. } \\
\text { Más información. }\end{array}$ & $\begin{array}{l}\text { LABORATORIOS - CONSULTORIAS } \\
\text { Desde Piris damos servicio a laboratorios y consultorias } \\
\text { Si necesita miss información sobre nuestros productos a } \\
\text { quilere solicitar muestras póngase en contacto con } \\
\text { nosotros. } \\
\text { Más información : }\end{array}$ \\
\hline
\end{tabular}

Antes del nuevo sitio web, la relación con los clientes se realizaba mayoritariamente de forma personal (visitas comerciales), por teléfono y a través del correo electrónico. Con el nuevo sitio, y definido también gracias al WSCM, el sitio web actúa como canal de captación de clientes potenciales. Esto se realiza gracias a la incorporación de un sistema de formularios automatizados, disponibles en la ficha de todos los productos. (Figura 5).

Podemos afirmar que, en este caso de uso, el WSCM resultó ser una herramienta muy eficiente para abordar el diseño estratégico del sitio web. Además, la naturaleza visual del modelo hizo que fuera muy sencillo trasladar los objetivos de los responsables de este sitio web a su diseño visual y a la programación.

\subsection{El WebSite Canvas Model aplicado a un e-commerce: Calperetmitjans.com}

Este caso de uso corresponde a la aplicación del modelo a una tienda online. Cal Peret Mitjans es una masía catalana que se dedica al cultivo del calçot (una variedad de cebolla) que es la base de las populares calçotades (un plato típico de la gastronomía catalana). Estos agricultores, que distribuían sus productos mediante intermediarios, decidieron crear una identidad corporativa (una marca) y lanzar una tienda online. Su objetivo era vender directamente los productos de su huerta al consumidor. Para idear la marca y el sitio web de estos agricultores se utilizó el WSCM.

En este caso, al tratarse de una tienda online con un número limitado de productos y escasa competencia, el proceso de aplicación del WSCM (realizado en octubre de 2015) fue realmente ágil. A continuación, se describe cómo ayudó este modelo a idear y concebir esta tienda online, especialmente su propuesta estratégica de valor en la web y su traslado al diseño del sitio.

En primer lugar, el benchmarking reveló que las principales debilidades de los sitios web de la competencia eran la desactualización de sus diseños, muy poco atractivos, y su incapacidad para la visualización de sus contenidos en dispositivos 
Figura 5. Captura de pantalla: Sistema de formularios automatizados e individuales para cada producto

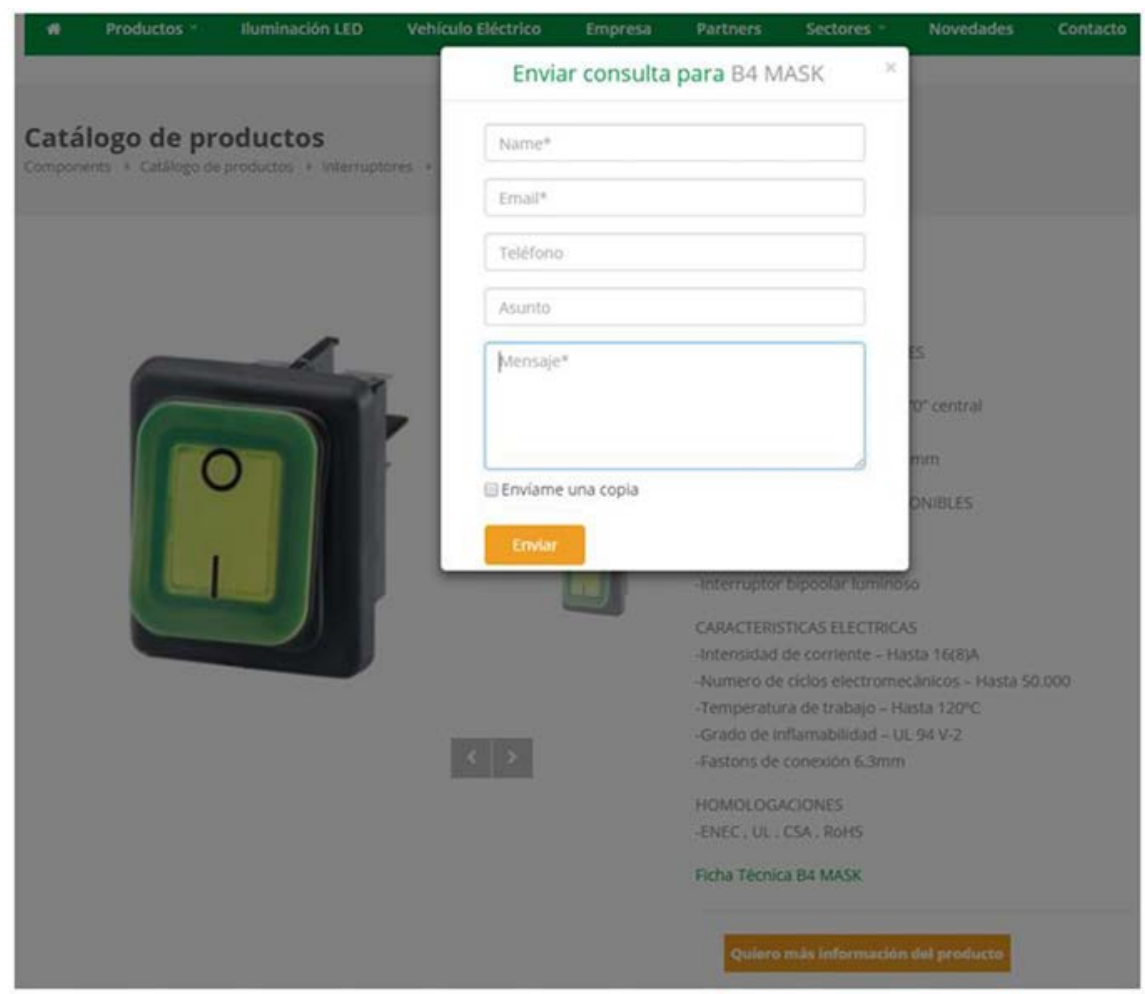

móviles. También se constató que el uso de URLs no amigables era bastante común en estas páginas, lo que dificulta su comprensión para los robots de los buscadores. Cal Peret Mitjans aprovechó la detección con el WSCM de estas debilidades de la competencia, lanzando un sitio web bien optimizado para los buscadores y dispositivos móviles, logrando en muy poco tiempo un buen posicionamiento orgánico en buscadores.

Asimismo, el WSCM fue clave para identificar la propuesta de valor, que consistió en destacar la desintermediación. Es decir, en transmitir la promesa "De la tierra al plato" y reforzar la idea de la venta de calçots de cosecha propia (Figura 6). La estrategia fue clara, el usuario debía visualizar claramente este valor. Para ello, en la página de inicio de esta tienda online se muestran fotografías reales de sus plantaciones.

Vinculado al apartado SOLOMO (Social, Local y Móvil), se ha introducido en la sección de contacto de la tienda la imagen real en Google maps de la masía y sus campos de calçots (Figura 7). De este modo la localización de los cultivos apoya la propuesta de valor, aportando convencimiento al cliente del origen directo del producto. También la apuesta por la usabilidad en los dispositivos móviles, a diferencia de algunos competidores, fue otro factor impulsado desde el WSCM.
El WebSite Canvas Model de CalperetMitjans.com (Figura 8) resultó ser una herramienta eficiente para un tienda online, especialmente al identificar y trasladar la propuesta de valor al sitio, y al identificar las debilidades de sus competidores. En relación a este caso de uso, el éxito de su desarrollo quedó constatado ya que, a las pocas semanas del lanzamiento de la tienda online, esta iniciativa consiguió amortizar la inversión realizada.

\section{DISCUSIÓN}

A menudo las organizaciones no realizan una reflexión previa sobre el enfoque y las características que deben presentar sus sitios web. Esto se debe a que, con frecuencia, priorizan la inmediatez del desarrollo. La consecuencia es que acaban teniendo sitios web con secciones y contenidos estandarizados, que no aportan diferenciación alguna con respecto a otras instituciones o empresas, y que además no responden a sus necesidades institucionales.

En muchos casos, se utilizan wireframes o mockups (Pérez-Montoro y Codina, 2010) para trasladar la idea de los responsables del sitio web al diseñador. No obstante, con este procedimiento podemos caer en el error de obviar un adecuado diseño estratégico del sitio. 
Figura 6. Captura de pantalla. Página de inicio que destaca la propuesta de valor, consistente en la desintermediación

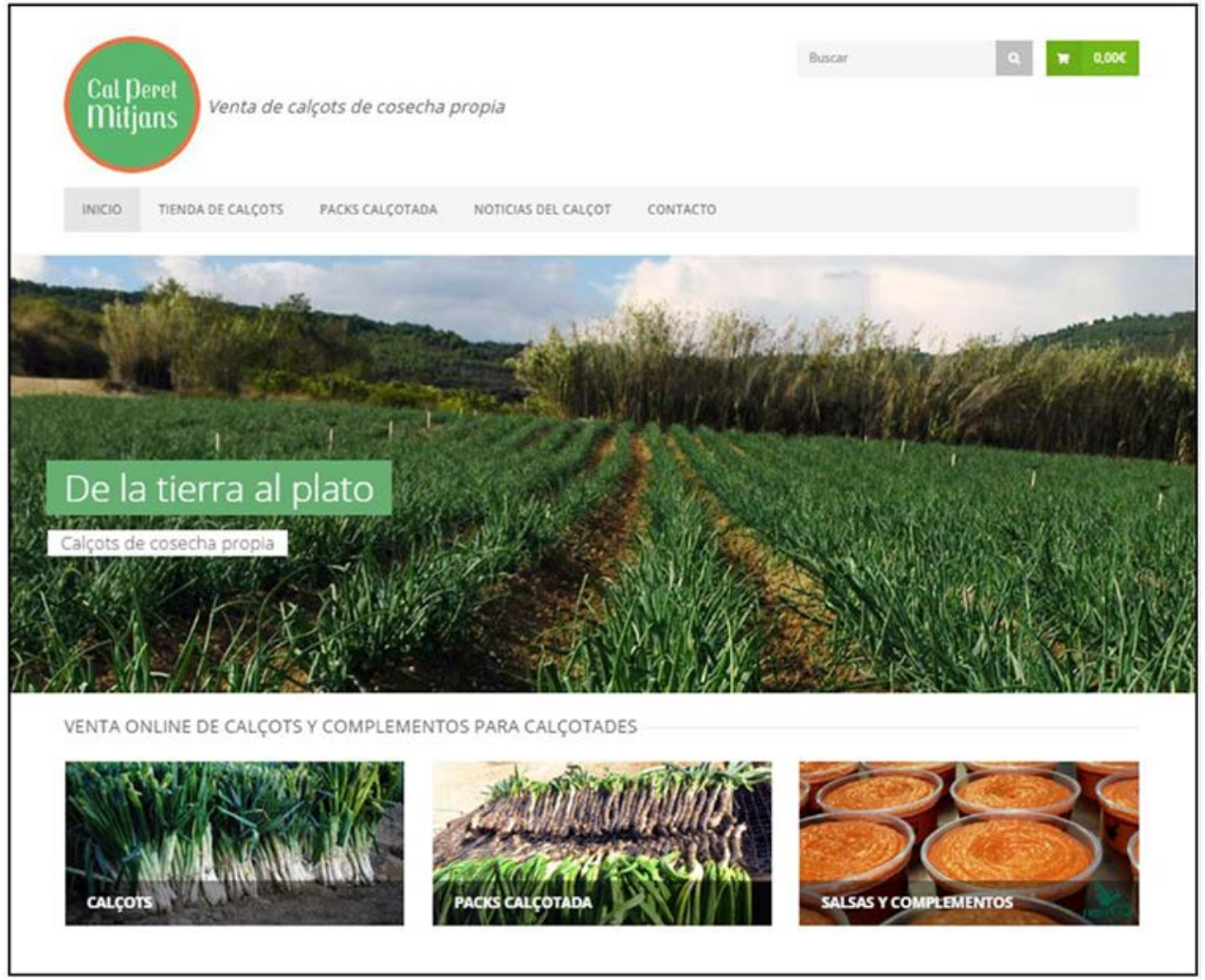

Figura 7. Captura de pantalla. Visualización de las plantaciones y la masía para la generación de confianza en el cliente

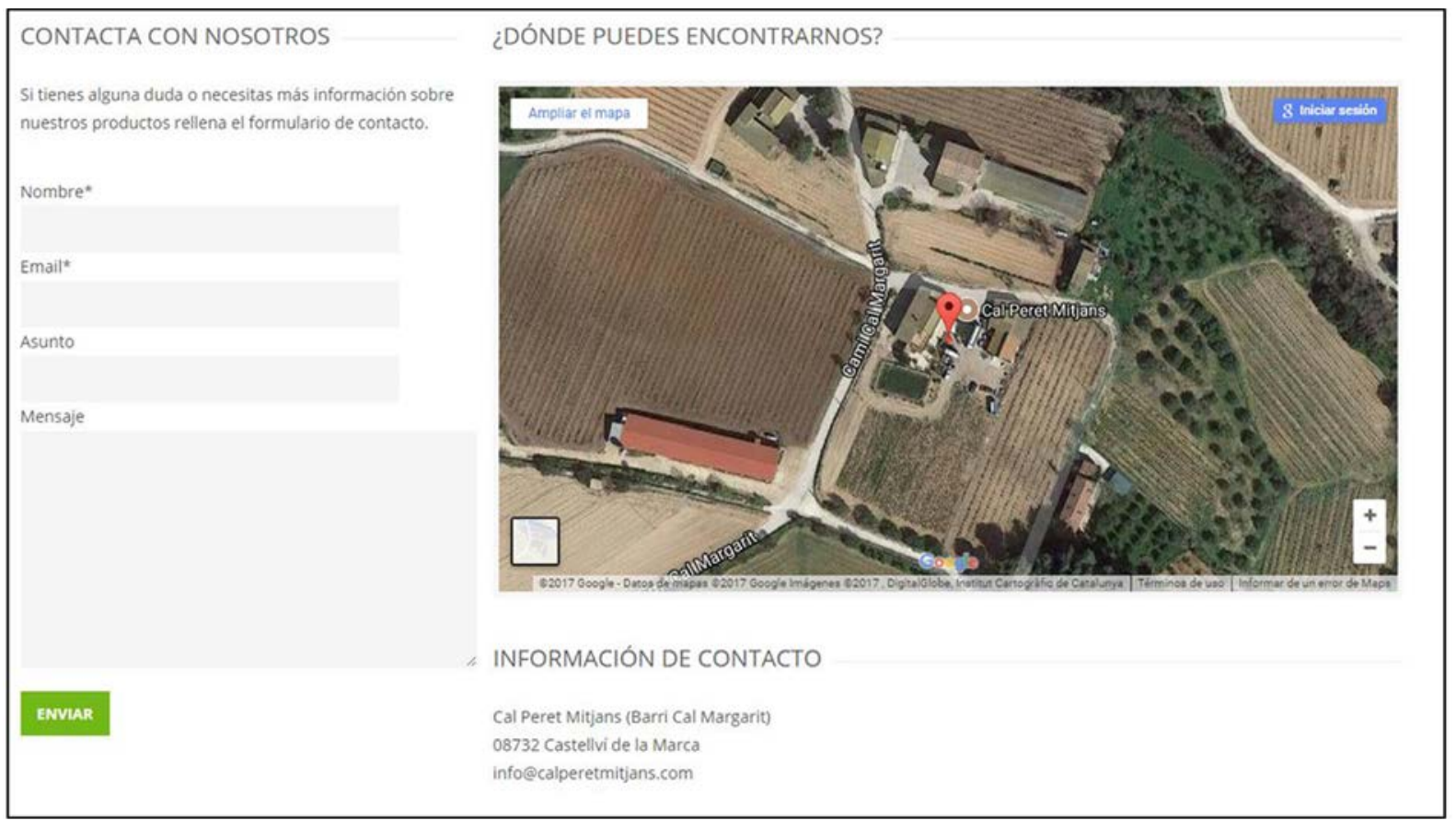


Figura 8. WSCM aplicado al e-commerce Calperetmitjans.com

\begin{tabular}{|c|c|c|c|c|c|}
\hline $\begin{array}{l}\text { 1.Actividad } \\
\text { Clave } \\
\text { Venta de } \\
\text { calçots online. }\end{array}$ & \multicolumn{2}{|c|}{$\begin{array}{l}\text { 2.Socios } \\
\text { Clave } \\
\text { Consultora } \\
\text { Web, SEO, SEM y } \\
\text { operador logístico. }\end{array}$} & $\begin{array}{l}\text { 3.Recursos } \\
\text { Clave } \\
\text { Recepción de los } \\
\text { pedidos y gestión } \\
\text { stock. } \\
\text { Atención al } \\
\text { cliente. }\end{array}$ & \multirow{3}{*}{$\begin{array}{l}\text { 9.Propuesta } \\
\text { de } \\
\text { Valor: } \\
\text { Desintermediación. } \\
\text { Venta al particular } \\
\text { de calçots de } \\
\text { denominación de } \\
\text { origen (calidad). } \\
\text { Directamente } \\
\text { desde la plantación } \\
\text { al domicilio del } \\
\text { comprador. }\end{array}$} & $\begin{array}{l}\text { 11.Branding } \\
\text { y promesa } \\
\text { Diseño cuidado. } \\
\text { Producto de payés. } \\
\text { "De la tierra al } \\
\text { plato". }\end{array}$ \\
\hline $\begin{array}{l}\text { 4.Relación } \\
\text { con los } \\
\text { Clientes } \\
\text { Formulario web, } \\
\text { correo electrónico } \\
\text { y teléfono. }\end{array}$ & \multicolumn{2}{|c|}{$\begin{array}{l}\text { 5.Segmentos } \\
\text { de Clientes } \\
\text { Clientes } \\
\text { particulares } \\
\text { y colectivos } \\
\text { (sociedades } \\
\text { gastronómicas y } \\
\text { restaurantes). }\end{array}$} & $\begin{array}{l}\text { 6.Canal } \\
\text { Internet web y } \\
\text { móvil. } \\
\text { Facebook como } \\
\text { canal de difusión } \\
\text { de contenido. }\end{array}$ & & $\begin{array}{l}\text { 12.Discurso } \\
\text { Persuasivo } \\
\text { Comunicación muy } \\
\text { visual. Fotografías } \\
\text { del producto. Tono } \\
\text { formal. }\end{array}$ \\
\hline \multicolumn{2}{|c|}{$\begin{array}{l}\text { 7.Estructura de } \\
\text { Costes } \\
\text { Desarrollo web, } \\
\text { mantenimiento, } \\
\text { agencia SEO - SEM y } \\
\text { el operador logístico. }\end{array}$} & \multicolumn{2}{|c|}{$\begin{array}{l}\text { 8. Fuente de } \\
\text { Ingresos } \\
\text { La venta de calçots } \\
\text { y productos } \\
\text { complementarios } \\
\text { (alcachofas, salsa, } \\
\text { baberos). }\end{array}$} & & $\begin{array}{l}\text { Arquitectura } \\
\text { Usabilidad } \\
\text { Primeras } \\
\text { posiciones } \\
\text { "Comprar calçots". } \\
\text { Al orientada a las } \\
\text { palabras clave. } \\
\text { Compra online fácil. }\end{array}$ \\
\hline \multicolumn{5}{|c|}{$\begin{array}{l}\text { 10.Benchmarking } \\
\text { Las principales debilidades de los sitios web de la competencia eran la desactualización } \\
\text { de sus diseños, muy poco atractivos, y su incapacidad para la visualización de sus } \\
\text { contenidos en dispositivos móviles. También se constató que el uso de URLs no } \\
\text { amigables era bastante común en estas páginas, lo que dificulta su comprensión para } \\
\text { los robots de los buscadores. }\end{array}$} & $\begin{array}{l}\text { 14.SoLoMo } \\
\text { Se apuesta por } \\
\text { Facebook. } \\
\text { Vista en Google } \\
\text { maps de la masía y } \\
\text { sus campos de } \\
\text { calçots. } \\
\text { E-commerce } \\
\text { adaptado a móvil. }\end{array}$ \\
\hline
\end{tabular}

Esta problemática ya ha sido constatada por autores como González y otros (2013). Estos autores señalan la necesidad de las organizaciones de evaluar la estrategia online relacionada con el sitio web de la compañía. Proponen un índice que mide una parte de la estrategia web relacionada con la sede online. Sin embargo, no abordan el estudio de la estrategia del sitio con una perspectiva global. En su trabajo se centran en estudiar las acciones que permiten que el usuario sea atraído a la página de la organización.

Por su lado, Fisher y otros (2007) proponen el concepto de "madurez de la estrategia del sitio". Estos autores asocian mayor desarrollo estratégico con mayor calidad del sitio web. No obstante, pese a la importancia de esta relación directa, estos autores concluyen que la discusión académica es muy limitada con respecto a dicha correlación. Este trabajo, con la propuesta de este nuevo modelo, intenta contribuir a llenar este vacío.

El WSCM podría servir para consensuar entre los distintos departamentos el modelo de sitio web ideal para la organización. Gracias a esta herramienta se puede lograr un sistema para idear, compartir y sintetizar la información de los apartados estratégicos del sitio, para a continuación trasladar esta información al equipo de desarrollo.
Existe una gran variedad de trabajos sobre la calidad y sistemas de evaluación, especialmente orientados a portales turísticos (Fernández-Cavia y otros, 2013), e-commerce (Roig y PedrazaJimenez, 2016), gobiernos, banca (Wątróbski y otros, 2016) o cibermedios (Rodríguez-Martínez y otros, 2012). No obstante, la novedad de nuestro modelo radica en que complementa a los actuales sistemas de evaluación para mejorar el componente estratégico de los sitios web. Siendo un sistema accesible y práctico para todo tipo de organización independientemente de su dimensión.

Los casos de uso muestran como el WSCM es una herramienta válida para las empresas que abordan la ideación de un sitio web. Este sistema les permite disponer de pautas para identificar los aspectos clave de su estrategia y reportarlos de forma sintética en un canvas.

Sin duda, la aplicabilidad del sistema vendrá dada por la adopción del WSCM en los entornos profesional y académico. De ahí la importancia de la difusión del sistema para que sea adoptado en futuros desarrollos web. Además, sería aconsejable su introducción como materia de estudio en los ámbitos del diseño y desarrollo de sitios web. 


\section{CONCLUSIONES}

El ámbito de los sistemas de análisis aborda disciplinas consolidadas con terminologías consensuadas, tales como la experiencia de usuario, la interactividad, la arquitectura web, la usabilidad, la accesibilidad o el posicionamiento orgánico en buscadores.

Tradicionalmente los estudios y sistemas de análisis propuestos para la evaluación de sitios web se centran en valorar la eficacia y calidad de los contenidos. También en analizar la comunicación con los usuarios. Entre estos sistemas destaca, por ejemplo, la metodología de evaluación desarrollada, entre otros, por los profesores Codina (2008) y Pedraza, y de amplia aplicación en trabajos de académicos y de investigación (Rodríguez-Martínez y otros, 2012).

Aunque el WSCM puede actuar como complemento de otros sistemas de análisis existentes (Sanabre, 2015), su principal aplicación se circunscribe al campo del diseño estratégico de sitios web. Este ámbito se caracteriza por hallarse aún en una fase inicial. En consecuencia, las herramientas de ideación y concepción estratégica de sitios web son escasas. Esto propicia que un sitio web que responde a una calidad evaluada como correcta o incluso excelente, pueda carecer de una lógica de negocio bien ideada, y estar condenado al fracaso por falta de una adecuada concepción.

EI WSCM intenta dar respuesta a esta problemática. Como herramienta de ideación, su aplicación se produce en una etapa previa al diseño funcional y el desarrollo, y tiene como resultado la identificación de los criterios estratégicos específicos que propician la consecución de los objetivos de cada sitio web. Probablemente, una de las principales aportaciones de este trabajo sea la propuesta e interrelación de los catorce apartados del WSCM, que facilitan la identificación de estos criterios en cada caso.

Por último, en relación a estos apartados y su funcionamiento, hay que destacar el carácter visual y sintético del WebSite Canvas Model. Este sistema ofrece una visión compartida de lo que se espera que sea el sitio web. Además, a través de un único documento facilita la comprensión y el trabajo colaborativo, aportando una síntesis global resumida visualmente en un lienzo.

De esta manera, el WebSite Canvas Model se erige como una herramienta novedosa para la ideación estratégica, que identifica y trata de forma explícita, visual y concisa los elementos clave que pueden propiciar el éxito de un proyecto web. Es además una herramienta de consenso, pues permite compartir y acordar fácilmente estos elementos entre las partes implicadas en el diseño y el desarrollo del sitio web.

Finalmente, vamos a retomar las preguntas de investigación para proceder a su examen:

P.1. ¿Es posible trasladar el denominado Canvas Model al ámbito de la ideación y diseño de sitios web?

Hemos podido trasladar el Canvas Model a un modelo que, una vez testado y validado, entendemos da respuesta afirmativa a esta pregunta, pudiendo considerarse una nueva aportación en este ámbito.

P.2. ¿Cuáles son las principales características en las que debe hacer énfasis ese modelo?

Tal como hemos podido mostrar, entendemos que nuestro modelo presenta las siguientes características, a la vez posibles y deseables:

- Propicia la identificación de los factores claves para la definición estratégica del sitio web.

- Facilita la conceptualización colaborativa entre los departamentos implicados en el desarrollo.

- Permite abordar de forma más estructurada los requerimientos funcionales y técnicos del sitio web.

- Favorece unos resultados positivos en aspectos como la calidad de contenidos, funcionalidades y/o servicios.

- Es útil para revisar sitios web operativos, pues identifica sus fortalezas y debilidades, así como las posibles mejoras que pueden realizarse en ellos.

- Es útil para estudiar los sitios web competidores (estudios de benchmarking).

- Sirve para detectar buenas prácticas en sitios web de éxito.

- Sirve para detectar debilidades de los sitios web competidores.

- $\quad$ Y todo ello plasmado de forma sintética y visual en un canvas o lienzo.

P.3. ¿Es factible la validación de un modelo con estas características a través de casos de uso?

La aplicación de nuestra herramienta en los casos de uso ha permitido probar y validar el modelo en la industria. El sistema ha facilitado el diseño y el consenso entre los departamentos implicados en el sitio web. A su vez, esto ha ayudado al equipo de desarrollo web a introducir los aspectos estratégicos en el sitio. Todo ello ha redundado en 
una mayor eficiencia en el tiempo para su implementación, ha evitado errores que podrían haber afectado la evolución del desarrollo y, en suma, ha propiciado que los proyectos lleguen a un buen fin.

\section{AGRADECIMIENTOS}

Este trabajo ha sido parcialmente financiado por los proyectos del Plan Nacional de investigación:

- "El turista en la Web: hábitos informacionales y selección de destino turístico. ITOURIST". CSO201459896-P (I+D MINECO 2015-2017). Ministerio de Economía y Competitividad (España).

- "Creación y contenido interactivo en la comunicación de información audiovisual: audiencias, diseño, sistemas y formatos". CSO2015-64955-

\section{REFERENCIAS}

Campos-Freire, F. (2015). Adaptación de los medios tradicionales a la innovación de los metamedios. El Profesional de la Información, 24 (4), 441-450. https://doi. org/10.3145/epi.2015.jul.11

Cicero, S. (2013). De los Modelos de Negocio al Diseño de Plataformas. Disponible en: https://platformdesigntoolkit.com/wp-content/docs/Platform-Design-ToolkitWhitepaper-ESP.pdf [Fecha de consulta 10/03/2018].

Codina, L. (2000). Evaluación de recursos digitales en línea: conceptos, indicadores y métodos. Revista Española de Documentación Científica, 23 (1), 9-44. https://doi.org/10.3989/redc.2000.v23.i1.315

Codina, L. (2008). Evaluación de calidad en sitios web. Metodología de proyectos de análisis sectoriales y de realización de auditorías (v. 2008). Barcelona: UPF. Área de Biblioteconomía y Documentación. Departamento de Periodismo y de Comunicación Audiovisual. https:// www.lluiscodina.com/wp-content/uploads/2014/04/ procedimientos2008.pdf

Dalton, R. (2007). The Forces of User Experience. http:// mauvyrusset.com/2007/06/16/the-forces-of-user-experience/

Denzin, N. K.; Lincoln, Y. S. (2011). The Sage handbook of qualitative research. Thousand Oaks, California: Sage.

Fernández-Cavia, J.; Díaz-Luque, P.; Huertas, A; Rovira, C.; Pedraza-Jiménez, R.; Sicilia, M.; Míguez, M. I. (2013). Marcas de destino y evaluación de sitios web: una metodología de investigación. Revista Latina de Comunicación Social, 68. https://doi.org/10.4185/ RLCS-2013-993

Fisher, J.; Craig, A.; Bentley, J. (2007). Moving from a Web Presence to e-Commerce: The Importance of a Business-Web Strategy for Small-Business Owners. Electronic Markets, 17 (4), 253-262. https://doi. org/10.1080/10196780701635864
C4-2-R (MINECO/FEDER). Ministerio de Economía y Competitividad (España).

\section{ACKNOWLEDGMENTS}

This work has been partially supported by the following research projects funded by the Spanish Ministry of Economy and Competitiveness:

- "The tourist on the Web: informational habits and destination choice. ITOURIST". CSO201459896-P (I+D MINECO 2015-2017). Ministerio de Economía y Competitividad (España).

- "Interactive content in audiovisual communication: audience, design systems and formats". CSO201564955-C4-2-R (I+D MINECO 2016-2018). Ministerio de Economía y Competitividad (España).

Garrett, J. J. (2011). Elements of user experience, the: user-centered design for the web and beyond (2. a edición). San Francisco: New Riders.

González, O.; Banegil T.; Buenadicha, M. (2013). El índice cuantitativo de calidad web como instrumento objetivo de medición de la calidad de sitios web corporativos. Investigaciones Europeas de Dirección y Economía de la Empresa 19 (1), 16-30. https://doi. org/10.1016/j.iedee.2012.07.004

Hernández, B.; Jiménez, Julio; Martín, M.J. (2009). Key website factors in e-business strategy. International Journal of Information Management, 29 (5), 362-371. https://doi.org/10.1016/j.ijinfomgt.2008.12.006

Hernández, B.; Jiménez, J.; Martín, M.J. (2010). Efecto de la calidad de un sitio web sobre el tráfico recibido. El caso de la banca electrónica en España. Information Research, 15 (2).

Jiménez-Iglesias, L.; Pérez-Montoro, M.; Sánchez-Gómez, L. (2017). Diseño de información digital: revisión y clasificación de indicadores heurísticos para contenidos web. El Profesional de la Información, 26 (6), 1029-1046. https://doi.org/10.3145/epi.2017.nov.03

Kaur, S.; Gupta, S.K. (2014). Key aspects to evaluate the performance of a commercial website. International Journal of Computer Applications, 1 (1), 1-5.

Maurya, A. (2012). Running lean: iterate from plan A to a plan that works. Sebastopol: O'Reilly Media, Inc.

Montalvo-Castro, J. (2016). Emprendimientos digitales y diseño de modelos de negocio: investigación aplicada en estudiantes de la Carrera de Comunicación. Contratexto, (25), 155-170. https://doi.org/10.26439/contratexto2016.n025.656

Mora, A.; Riera, D.; Gonzalez, C.; Arnedo-Moreno, J. (2015). A literature review of gamification design frameworks. En Games and virtual worlds for serious 
applications (VS-Games), 2015 7th international conference on (1-8). IEEE. https://doi.org/10.1109/VSGAMES.2015.7295760

Nielsen, J. (1999). Designing web usability: The practice of simplicity; Thousand Oaks: New Riders Publishing.

Nielsen, J. (1994). Usability inspection methods. En: Conference companion on Human factors in computing systems, pp. 413-414. Boston, Massachusetts: ACM. https://doi.org/10.1145/259963.260531

Olsen, G. (2003). Approaches to User Experience Design. http://boxesandarrows.com/files/banda/expanding_the approaches_to_user_experience/uxapproachesmodel.pdf

Osterwalder, A; Pigneur, Y. (2010). Business Model Generation: A Handbook for Visionaries, Game Changers, and Challengers. New Jersey: John Wiley \& Sons.

Osterwalder, A.; Pigneur, Y.; Clark, T. (2012). Tu modelo de negocio. Barcelona: Grupo Planeta.

Pedraza-Jiménez, R; Codina, L.; Guallar, J. (2016). Calidad en sitios web: método de análisis general, e-commerce, imágenes, hemerotecas y turismo. Barcelona: Editorial UOC.

Pedraza-Jiménez, R.; Banco, S.; Codina, L.; Cavaller, V. (2013). Diseño conceptual y especificación de requerimientos para el desarrollo y rediseño de sitios web. El Profesional de la Información, 22 (1), 74-79. https:// doi.org/10.3145/epi.2013.ene.10

Pérez-Montoro, M.; Codina, L. (2010). Software de prototipado para la arquitectura de la información: funcionalidad y evaluación. El Profesional de la Información, 19 (4), 417-424. https://doi.org/10.3145/epi.2010.jul.12

Piñeiro-Naval V.; Igartua, J.J.; Marañón, F. (2017). El diseño de las sedes web municipales de España. Una propuesta metodológica para su análisis. Revista Española de Documentación Científica, 40 (1), e164. https://doi.org/10.3989/redc.2017.1.1368

Rodríguez-Martínez, R.; Codina, L.; Pedraza-Jiménez, R. (2010). Cibermedios y web 2.0: modelo de análisis y resultados de aplicación. El Profesional de la Informacion, 19 (1), 35-44. https://doi.org/10.3145/epi.2010. ene.05

Rodríguez-Martínez, R.; Codina, L. ; Pedraza-Jiménez, R. (2012). Indicadores para la evaluación de la calidad en cibermedios: análisis de la interacción y de la adopción de la Web 2.0. Revista Española de Documentación Científica, 35 (1), 61-93. https://doi.org/10.3989/ redc. 2012.1 .858

Roig, N.; Pedraza-Jimenez, R. (2016). Comercio electrónico. En: Pedraza-Jimenez, R. Codina LI.; Guallar, J. (Coordinadores) Calidad en sitios web. Método de análisis general, e-commerce, imágenes, hemerotecas y turismo. Colección EPI scholar. Editorial UOC: Barcelona.

Rosenfeld, L.; Morville, P. (2006). Information architecture for the world wide web (3.a ed.). Sebastopol: O'Reilly Media, Inc., p. 264.

Sanabre, C. (2015). Un modelo para el análisis y concepción de sitios web: El WebSite Canvas Model aplicado a Eldiario.es. Hipertext.net, Anuario Académico sobre Documentación Digital y Comunicación Interactiva, 13. http://doi.org/10.2436/20.8050.01.20

Wątróbski, J.; Ziemba, P.; Jankowski, J.; Wolski, W. (2016). PEQUAL- E-commerce websites quality evaluation methodology. En Computer Science and Information Systems (FedCSIS), Federated Conference on, pp. 1317-1327; IEEE. https://ieeexplore.ieee.org/ document/7733416 